\title{
Will exercise mimetics hold promise?
}

Dario Coletti ${ }^{1,2}$ and Sergio Adamo ${ }^{*}$

${ }^{1}$ Department of Anatomical, Histological, Forensic and Orthopedic Sciences, Histology and Medical Embryology Section, Sapienza University of Rome, Italy ${ }^{2}$ Department of Biological Adaptation and Ageing B2A (CNRS UMR 8256 - INSERM ERL U1164 - UPMC P6), Pierre et Marie Curie University, Paris 6, France

\section{Abbreviations}

AMPK: AMP-Activated Protein Kinase; AICAR: 5-Amino-1-BetaD-Ribofuranosyl-Imidazole-4-Carboxamide; BDNF: Brain Derived Neurotrophic Factor; COPD: Chronic Obstructive Pulmonary Disease; GW1516: \{4-[(\{4-methyl-2-[4-(trifluoromethyl)phenyl]-1,3-thiazol-5yl\}methyl)sulfanyl]-2-methylphenoxy\}acetic acid; IGFs: Insulin-Like Growth Factors; PGC-1a: Peroxisome Proliferator-Activated Receptor Gamma Coactivator 1- $\alpha$; Ppars: Peroxisome Proliferator-Activated Receptors.

Skeletal muscle has long been known as the target of several growth factors and hormones, including IGFs, steroids, thyroid and neurohypophyseal hormones, often regulating both muscle development and homeostasis in postnatal life, as summarized in classical as well as more recent reviews [1-4]. Such a complex hormonal regulation is not surprising, if one considers the many diverse functions muscle exerts: mechanical force production, body temperature regulation and metabolic storage due to its protein content. Active muscle accounts for over $90 \%$ of total body energy expenditure.

Much more recent is the view of muscle as the source of several hormones [5-7] making skeletal muscle the largest endocrine gland of the organism and probably the most complex, due to the number (hundreds) of peptides constituting its secretome.

\section{A New View of the Exercised Muscle as an Endocrine Organ}

Some muscle products (myokines) have a paracrine function, regulating muscle mass (myostatin, IL-4, IL-6). Others, such as IL-8, irisin and BDNF, modulate adipose tissue metabolism, or, for example, IL- 6 and additional myokines are known to act on liver, bone, immune and vascular systems. This points out to skeletal muscle, a highly vascularized organ, as one capable of affecting several targets through endocrine mechanisms. Indeed, the endocrine functions of skeletal muscle have been long suspected on the basis of clinical findings [8]: all the abnormalities characterizing the metabolic syndrome are linked to a lack of physical activity, as are an increased risk of cancer, cardiovascular diseases and osteoporosis [9-11]. Thus, exercising muscles do indeed regulate the metabolism of many distant tissues via myokines. The molecular identity of the myokines, their signaling to target tissues, the metabolic responses elicited by such signals, all contribute to a complex metabolic network which is being investigated at the molecular and physiologic levels [12].

\section{Exercise Mimetics: Possible Applications and Misuses}

The idea that targeting the myokine network can mimic the signals generated by exercising muscle is the rational basis for a novel family of drugs, the exercise mimetics $[13,14]$. Exercise mimetics (EM) are a heterogeneous group of compounds that share the ability to induce pathways which are physiologically activated by exercise, thus stimulating endurance and rescuing muscle atrophy [15-17]. GW1516 (also known as GW501516) or AICAR, among others, are activators of AMPK, PPARs and PGC-1, a complex of effector proteins, transcription factors and co-activators. This pathway ultimately leads to the activation of both mitochondriogenesis and muscle oxidative metabolism, as it would in response to an increased AMP/ATP ratio, physiologically following exercise and energy consumption. Worth noting, EM such as GW1516 have shown to be bioactive in humans [18], suggesting a readily translational application for these drugs. Also the antioxidant resveratrol has been shown to synergize with exercise, positively affecting muscle performance, mitochondriogenesis and insulin sensitivity: its mechanism of action, however, which apparently goes beyond its antioxidant effect, is still unclear [19].

Since EM make myofibers more energy-efficient and fatigueresistant by reducing glycogen dependency and increasing fatty acid oxidation, many possible applications in pathology are proposed, including the pharmacological treatment of cancer- and diabetesassociated cachexia and sarcopenia [20,21].

Among possible applications for the general population, EM could be used to avoid many consequences of inactivity due to aging, reduced gravity, forced immobilization or life style: those involve developing insulin resistance, fat accumulation, metabolic syndrome, type 2 diabetes, all conditions characterized by high social costs. It should be pointed out that, while GW1516 synergized with exercise in inducing endurance in mice, it increased muscle gene expression without significantly modifying endurance when given to sedentary mice. Conversely, AICAR was shown to both induce metabolic gene expression and enhance running endurance in sedentary mice [22]. The use of "exercise pills" to respond to the increasingly serious problem of physical inactivity has been discussed and commented elsewhere [23], and the ability of EM to fully mimic exercise has been questioned $[24,23]$. Needless to say, the toxicities of the various EM should be seriously considered and pondered in the context of an evident therapeutic indication.

As enhancers of physical performance, EM treatments would be considered doping agents in sport. Indeed, in the original report by Matsakas and Narkar, AICAR amplified normal mouse response to exercise and induced greater endurance adaptation than exercise alone, thus raising concern of substance abuse by athletes. In particular, endurance performances in sports such as marathon, biking and long distance swimming could be greatly enhanced by EM. However, tests are reportedly available for detecting both GW1516 and AICAR and their metabolic by-products $[25,26]$.

*Corresponding author: Sergio Adamo, DAHFMO, Histology and Medical Embryology Section, Sapienza University Via A. Scarpa 16, 00161, Rome, Italy, Tel: +39 064976 6756; E-mail: sergio.adamo@uniroma1.it

Received April 15, 2015; Accepted April 16, 2015; Published April 21, 2015

Citation: Coletti D, Adamo S (2015) Will exercise mimetics hold promise? J Pharmacovigilance 3: e138. doi:10.4172/2329-6887.1000e138

Copyright: $\odot 2015$ Coletti D, et al. This is an open-access article distributed under the terms of the Creative Commons Attribution License, which permits unrestricted use, distribution, and reproduction in any medium, provided the original author and source are credited. 


\section{Sweating Hard or Swallowing Pills?}

EM could be the ideal treatment for patients who cannot have access to or need withdrawing from endurance training programs due to various circumstances. In addition, EM could be exploited to target specific metabolic pathways, which are altered in some muscle pathologies or in conditions linked to aging or forced immobility. The potential for clinical use of EM exists: GW1516 and AICAR may exert effects on sugar and lipid metabolism, thus treating or delaying the establishment of the metabolic syndrome. GW1516 can enhance the response to even moderate exercise, whereas AICAR might be used also when no exercise is possible.

However, physical exercise has systemic effects and it is highly unlikely that a single compound or pathway can mimic the complexity of exercise effects on the organism. Accordingly, the use of EM for organ failure, such as COPD, which is less heavily characterized by muscle wasting than cancer, remains speculative [27]. Even though we cannot exclude general EM effects mediated by selective muscle stimulation, such evidence is missing to date and EM impact on different organs needs to be further elucidated. Research must proceed by better characterizing the complex network of the myokines and their mechanisms of action, and clarifying, at the molecular level, the muscle response to exercise. Furthermore, pharmacological research should strive to develop new molecules capable of interfering with those complex mechanisms with minimal toxicity, thereby pursuing important aims such as decreasing the social costs of the metabolic syndrome and contributing to cancer prevention.

\section{References}

1. Florini JR (1987) Hormonal control of muscle growth. Muscle Nerve 10: 577 598

2. Solomon AM, Bouloux PM (2006) Modifying muscle mass - the endocrine perspective. J Endocrinol 191: 349-360.

3. Musarò A, Giacinti C, Pelosi L, Dobrowolny G, Barberi L, et al. (2007) Stem cell-mediated muscle regeneration and repair in aging and neuromuscular diseases. Eur J Histochem 51: 35-44.

4. Costa A, Rossi E, Scicchitano BM, Coletti D, Adamo S, et al. (2014) Neurohypophyseal hormones: novel actors of striated muscle development and homeostasis. Eur J Trasl Med 24: 217-25

5. Pedersen BK, Febbraio MA (2008) Muscle as an endocrine organ: focus on muscle-derived interleukin-6. Physiol Rev 88: 1379-1406.

6. Pedersen BK, Febbraio MA (2012) Muscles, exercise and obesity: skeletal muscle as a secretory organ. Nat Rev Endocrinol 8: 457-465

7. So B, Kim H-J, Kim J, Song W (2014) Exercise-induced myokines in health and metabolic diseases. Integr Med Res 3:172-179.

8. GOLDSTEIN MS (1961) Humoral nature of the hypoglycemic factor of muscular work. Diabetes 10: 232-234.

9. Booth FW, Chakravarthy MV, Gordon SE, Spangenburg EE (2002) Waging war on physical inactivity: using modern molecular ammunition against an ancient enemy. J Appl Physiol (1985) 93: 3-30.

10. Nocon M, Hiemann T, Müller-Riemenschneider F, Thalau F, Roll S, et al. (2008) Association of physical activity with all-cause and cardiovascular mortality: a systematic review and meta-analysis. Eur J Cardiovasc Prev Rehabil 15: 239 246.

11. Wolin KY, Yan Y, Colditz GA, Lee I-M (2009) Physical activity and colon cancer prevention: a meta-analysis. $\mathrm{Br} \mathrm{J}$ Cancer 100: 611-616.

12. Muñoz-Cánoves $P$, Scheele C, Pedersen BK, Serrano AL (2013) Interleukin-6 myokine signaling in skeletal muscle: a double-edged sword? FEBS J 280 4131-4148.

13. Matsakas A, Narkar VA (2010) Endurance exercise mimetics in skeletal muscle. Curr Sports Med Rep 9: 227-232.

14. Vina J, Sanchis-Gomar F, Martinez-Bello V, Gomez-Cabrera MC (2012) Exercise acts as a drug; the pharmacological benefits of exercise. $\mathrm{Br}$ Pharmacol 167: 1-12.

15. Brault JJ, Jespersen JG, Goldberg AL (2010) Peroxisome proliferator-activated receptor gamma coactivator 1alpha or 1beta overexpression inhibits muscle protein degradation, induction of ubiquitin ligases, and disuse atrophy. J Biol Chem. 285:19460-19471.

16. Tadaishi M, Miura S, Kai Y, Kawasaki E, Koshinaka K, et al. (2011) Effect of exercise intensity and AICAR on isoform-specific expressions of murine skeletal muscle PGC-1a mRNA: a role of 32 -adrenergic receptor activation. Am J Physiol Endocrinol Metab 300: E341-349.

17. Fan W, Atkins AR, Yu RT, Downes M, Evans RM (2013) Road to exercise mimetics: targeting nuclear receptors in skeletal muscle. J Mol Endocrinol 51 T87-87T100.

18. Sprecher DL, Massien C, Pearce G, Billin AN, Perlstein I, et al. (2007) Triglyceride: High-Density Lipoprotein Cholesterol Effects in Healthy Subjects Administered a Peroxisome Proliferator Activated Receptor d Agonist. Arterioscler Thromb Vasc Biol 27: 359-365.

19. Mankowski RT, Anton SD, Buford TW, Leeuwenburgh C (2015) Dietary Antioxidants as Modifiers of Physiologic Adaptations to Exercise. Med Sci Sports Exerc.

20. Lenhard JM, Lancaster ME, Paulik MA, Weiel JE, Binz JG, et al. (1999) The RXR agonist LG100268 causes hepatomegaly, improves glycaemic contro and decreases cardiovascular risk and cachexia in diabetic mice suffering from pancreatic beta-cell dysfunction. Diabetologia 42: 545-554.

21. Moresi V, Pigna E, Aulino P, Berardi E, Rossi E, et al. (2013) Mechanisms underlying exercise-mediated rescue of cachexia. Eur J Transl Myol 23: 14-15.

2. Narkar VA, Downes M, Yu RT, Embler E, Wang YX, et al. (2008) AMPK and PPARdelta agonists are exercise mimetics. Cell 134: 405-415.

23. Warden SJ, Fuchs RK (2008) Are "exercise pills" the answer to the growing problem of physical inactivity?. Br J Sports Med 42: 862-863.

24. Rantzau C, Christopher M, Alford FP (2008) Contrasting effects of exercise, AICAR, and increased fatty acid supply on in vivo and skeletal muscle glucose metabolism. J Appl Physiol 104: 363-370.

25. Thevis M, Geyer H, Thomas A, Schänzer W (2011) Trafficking of drug candidates relevant for sports drug testing: Detection of non-approved therapeutics categorized as anabolic and gene doping agents in products distributed via the Internet. Drug Test Anal 3: 331-336.

26. Pokrywka A Cholbinski B, Kaliszewski P, Kowalczyk K, Konczak D, et al. (2014) Metabolic modulators of the exercise response: doping control analysis of an agonist of the peroxisome proliferator-activated receptor d (GW501516) and 5-aminoimidazole-4-carboxamide ribonucleotide (AICAR). J Physio Pharmacol 65: 469-476.

27. Remels AH, Gosker HR, Schrauwen P, Langen RC, Schols AM (2008) Peroxisome proliferator-activated receptors: a therapeutic target in COPD? Eur Respir J 31: 502-508. 